\title{
DEVELOPMENT OF E-LEARNING BASED RESOURCE ECONOMICS LECTURE MODEL IN FACING INDUSTRIAL REVOLUTION 4.0
}

\author{
Nuraini Asriati \\ Tanjungpura University, Pontianak, Indonesia \\ E-mail: nuraini.asriati@fkip.untan.ac.id
}

\begin{abstract}
In facing the industrial revolution 4.0 where technology plays its role the most. It also affects the education field in which the optimization of the use of instructional media and the evaluation needs to be upgraded. This research aims at revealing the implementation of the instructional model of e-learning based resource economics lectures. This research uses a development method in which there are qualitative and quantitative analyses. the data were collected using observation and distribution of questionnaires to 39 students attending the learning process. The results showed that (1) The implementation of the instructional model of e-learning based resource economics lectures in facing the industrial revolution 4.0 has been effective because there is careful planning. In addition to being suitable for the learning objectives, it is also in accordance with the students' needs. The success of e-learning is related to a consistent and integrated effort between lecturers, students, faculty, support staff, and administrators. (2) the use of e-learning as a medium for learning resources, delivery of material, and assignment of tasks in the learning process of Resource Economics is still less than optimal. It indicates that the existing facilities and infrastructure have not been well utilized by its users, either by students, lecturers, or other related parties. And (3) the results of the evaluation of the implementation of the instructional model have shown a good category, meaning that the e-learning instructional model applied in the lectures of resource economics for economics education students is good and meets the needs of the students and can increase students' motivation and understanding in learning as a basis for facing the era industrial revolution 4.0.
\end{abstract}

Keywords: Development of Lecture Model; Resource Economics; E-Learning

\section{INTRODUCTION}

The emergence of the industrial revolution 4.0 is marked by the era of distortion, namely the emergence of onlinebased (digital) industries. In this revolution, the role of innovation determines the competitiveness of a product in the market. In society, there is still a gap between industry and workforce readiness and even there have been difficulties in finding human resources who have the ability of data literacy (big data), technological literacy (coding, and understanding of $\mathrm{AI}$ ) and human literacy (humanities, communication and information), as facing the industrial revolution 4.0 requires various kinds of intelligence (Oosthuizen, 2016).

Industry 4.0 will provide benefits in terms of increasing productivity, efficiency, flexibility, and a high level of product customization for the industrial world. But on the other hand, every change can have other undesirable effects. According to Schwab (2015), the emergence of Industry 4.0 will have the effect of an extraordinary gap related to the "low-skill/low-pay" and "high-skill/high-pay" workforce associated with digital information and the internet.

Internet technology is a development of the previous generation of communication technology. Media such as the radio, television, videos, multimedia and other types of media have been used and can help improve the quality of education. Moreover, internet media which has interactive nature can be mass and interpersonal, and sources of information from various corners of the world are possible to become a media of education superior to previous generations and a challenge to the industrial revolution 4.0 in both formal and non-formal education systems. Because so far there has been a mismatch between training that is often given at the Job Training Center with the needs in the industry.

The rapid development of technology in the era of the industrial revolution 4.0 must be anticipated by higher education institutions. Where one's behavior and norms are affected by the learning process (Syamsuri, 2019), adjustments to the increasingly competitive business climate need to be made in the tertiary curriculum and educational 
methods which must also follow the development of technology and information.

Lectures via the internet are possible, and learning to adopt the Industrial Revolution 4.0 will improve work performance later (Tortorella et al., 2020). E-learning is an alternative educational media that is not restricted by space and time. The use of e-learning is inseparable from internet services. Because the learning techniques available on the internet are so complete, this will affect the teacher's task in the learning process. The use of appropriate e-learning instructional models will improve learning experiences (Shi et al., 2020).

E-learning, as a direct result of the integration of technology and education, has emerged as a powerful learning medium primarily using Internet technology (AlFraihat, Joy and Sinclair, 2020). In the past, the teaching and learning process in Higher Education was dominated by the role of lecturers called the era of teacher, where students only listened to lecturers' explanations. Then, the lecture process was dominated by the role of lecturers and books (the era of teacher and book) and at the moment the lecture process is dominated by the role of lecturers, books, and technology (the era of teacher, book and technology) including resource economics courses taught in the odd semester. According to the research results of Vodovar et al. (2020) students feel more satisfied with e-learning compared to conventional instruction.

Changes in the world entering the era of the industrial revolution 4.0 has become the basis of human life. Everything becomes borderless with unlimited use of computing and data because it is affected by the development of the internet and massive digital technology as the backbone of human movement and connectivity in various learning activities and processes in higher education.

Resource economics deals with the material economy of human, natural, and financial resources. Human resource economics is a branch of economics that deals with the principles of the use of human energy and the ability to meet human needs. Natural resource economics is also a branch of economics that addresses various techniques in utilizing natural resources that are available for the prosperity of many people. All stakeholders must follow the changing trends in technology and the learning environment related to technological advancement (Choudhury \& Pattnaik, 2020).

The novelty of this research is the application of e-learning applications in resource economics courses so that in the future it will become a solution and option in applying learning models in higher education. Therefore, along with the development of science and technology facing the industrial revolution 4.0 this resource economics material will be delivered on a web-based basis (E-Learning) to encourage the teaching team and research team to research developing a web-based resource economics lecturing model (E-Learning ). This study aims to reveal the implementation of the learning model in e-learning based resource economics lectures in facing the industrial revolution 4.0, reveal the optimization of the use of learning media in e-learning based resource economics lectures in facing the industrial revolution 4.0, and reveal the evaluation of the implementation of the learning model in e-learning based resource economics lectures in facing the industrial revolution 4.0.

\section{METHODOLOGY}

This study is development research of the e-learning based learning model to improve understanding of economic concepts of resources. The research subjects in this study were the third-semester students of Economics Education of the Teacher Training and Education of the Tanjungpura University in the 2018/2019 academic year with a total of 39 students. In addition to qualitative analysis, this research also uses quantitative analysis to reveal the evaluation of the implementation of learning models in lectures of resource economics in facing the industrial revolution 4.0.

The data collection technique in this study is the process of developing website-based e-learning. To obtain data about the process of developing website-based e-learning, the researcher used field notes to describe the stages of the development process of e-learning instruction through observation and expert validation data and questionnaires. To obtain data about validity, and practicality, e-learning was developed based on indicators of assessment. These data were obtained from resource economics lecturers and ICT experts. Validation data from experts were then reviewed to be used as input in revising/refining the e-learning instructional model developed.

The development of which measures chosen researchers refers to ten steps the implementation of the research and development strategy according to Borg and Ball (Sukmadinata 2009: 169 - 170 ), namely: (1) Research and data collection. The measurement of, needs a literature review, research on a small scale and taking in terms of value; (2) Which includes planning capabilities required, the research phase the formulation to, achieved by this research design or steps, research the possibility of testing limited in scope; (3) The development of the draft e-learning covering; development, lessons learned the learning process and the instrument of evaluation; (4) The trial of the starting pitch. The trial of a field on 5 to 10 students. During the tests of held observation, interviews and watchful such of the survey; (5) Revision of the results of the tryouts, fix or complete elearning the results of the tryouts; (6) Do the trials that wider at 15 until with 20 student test subject; (7) The improvement of e-learning based resource economics lecture test results on the field the second phase; (8) Test of the field which was held on 20 to 30 students. Testing is done through the survey, interview, and observation and analysis of the results; (9) Elearning based resource economics lecture made in the final phase of the trial based on the results of the third stage; (10) The implementation of e-learning based resource economics lecture in real situations in class and disseminate research results to be used by other teachers.

\section{RESULTS AND DISCUSSION}

\section{A. Implementation of the Learning Process Scenario in E- Learning Based Resource Economics Lectures}

Learning activities in e-Learning. The activity began with students praying before starting the lesson. After prayer, the lecturer explained the e-Learning instructional scenario to students and directed students to $\log$ in on the website esdm.dkampus.com. When all were logged in, on the website 
there were 2 parts of the material. The first was about Human Resource Economics and the second about Natural Resource Economics. Before starting with the material, the lecturer evaluated the students' knowledge about human resource economics.

The lecturer explained the material and opened the question session. Some students asked questions and the lecturer answered the questions directly. Then the lecturer continued the material on natural resource economics. Before discussing natural resource economics, the lecturer asked the students questions about natural resource economics and one of the students answered.

Then, the lecturer explained the material. After that, the lecturer divided the students into groups consisting of 1-13 logins, 1 login consists of 3 students. The students discussed the material that had been provided on the website. After completing the discussion, there were several groups or logins ready to present the results of the discussion, i.e. login 5 and 9. After login 5 and 9 completed the presentations, the lecturer evaluated the students' understanding of the e-Learning Resource Economics material and some students responded.

The lecturer concluded the material of the day and learning outcomes. The lecturer ended the learning with greetings. In detail, the steps of e-learning instructional scenarios can be described as follows: (1) The lecturer and students together opened the website esdm.dkampus.com and then clicked on the login button, (2) After the Web screen appeared, the lecturer and student entered their user names (the lecturer used Civil Servant Number while students using students number respectively). The password is the same number namely 12345678. (3) After the user name was entered according to their respective student number with password 12345678 , the homepage appeared on the screen. Then each student could open the material according to their respective logins. In the first stage, students clicked on the textbook to read the material on human and natural resource economics in relation to economic development, (4) On the home menu, there were two materials on human and natural resource economics. On the screen, there were also 14 questions divided into several groups and 40 users on this website. (5) After the students clicked on the teaching material, the title of the material appeared. The material will be readable if the student clicks on the file (6) After the students click on the file title of the teaching material, the material will appear as on the screen below, (7) After reading the material thoroughly on the monitor screen, the students were divided into several groups to discuss problems that related to the material on human and natural resource economics. Each group could only open their menus according to their logins, (8) After each student found their group, all groups entered their respective login menus which cannot be opened by other logins. To find out the material discussed by each group, they can click on the blue file according to each login so students get an assignment on the monitor screen.

After students clicked on the blue file with each login then students had discussed according to the material provided on each login as follows: LOGIN 1. Why is human resource development so important for national development? Explain !; LOGIN 2. What does it mean to improve the physical quality of human resources through nutrition and health? Explain!; LOGIN 3. Human investment is required in economic growth and development. Why? Explain !; LOGIN 4. The main problem faced by developing countries is the high level of unemployment. Why? And how do you solve the problem ?; LOGIN 5. In the era of globalization and free trade, a large population and people's economic power is a potential and at the same time a target for socioeconomic development both small and large scale. Why? Explain !; LOGIN 6. What is the difference between economics and natural resource economics? Explain and give examples; LOGIN 7. What does it mean: human needs are unlimited while the means of satisfying needs (resources) are limited?; LOGIN 8. What is the role of natural resources in economic development? LOGIN 9. What does it mean: the relationship between the number of resource goods and economic growth is positive while the relationship between economic growth and the availability of natural resources is negative? Explain and provide description !; LOGIN 10. What does the production function contain! Also, show the formula?; LOGIN 11. Describe and explain the relationship between population, economic growth, natural resource goods and the environment!; LOGIN 12. Draw the relationship curve between population, economic growth, natural resource and environmental goods and its analysis; LOGIN 13. Draw the curve between the Growth Rate and Pollution Rate and its analysis. The results of the discussion of each login can be sent or uploaded to the website. The last step after each login uploaded the results of the discussion, the e-learning activities were concluded and appeared on the monitor screen as below. Basically, it is the implementation or scenario. Web programming language to support instructional communication in online learning environments, taking into account the perspectives of students and teachers, identifies several new features that can contribute to the success of interactive e-learning systems in academic organizations (Farhan et al., 2019).

The learning process in e-learning based resource economics lectures ran effectively where $99 \%$ of the students successfully logged in and operated the Web used in the learning process. The role of emotions in e-learning is important for testing the affective-cognitive e-learning model with the relationship of e-learning, the learner's emotional reactions during learning, the cognitive processes of learners during learning, and learning outcomes (Mayer, 2019). The order of the process and learning by using electronic devices has an important role in making the unattractive learning process attractive for students. Learning that meets standards through the Internet, and the availability of Educational Resources provide great support to teachers when they need to develop education that uses available learning materials. (De Medio et al., 2020).

\section{B. Evaluation of the Implementation of the Learning Model in E-Learning Based Resource Economics Lectures}

The analysis of the evaluation of learning models in elearning based resource economics lectures used quantitative analysis in which information on how the learning process is carried out by students from several aspects of assessment. The evaluation of attractiveness, planning, learning process, and context is presented in Fig. 1. 


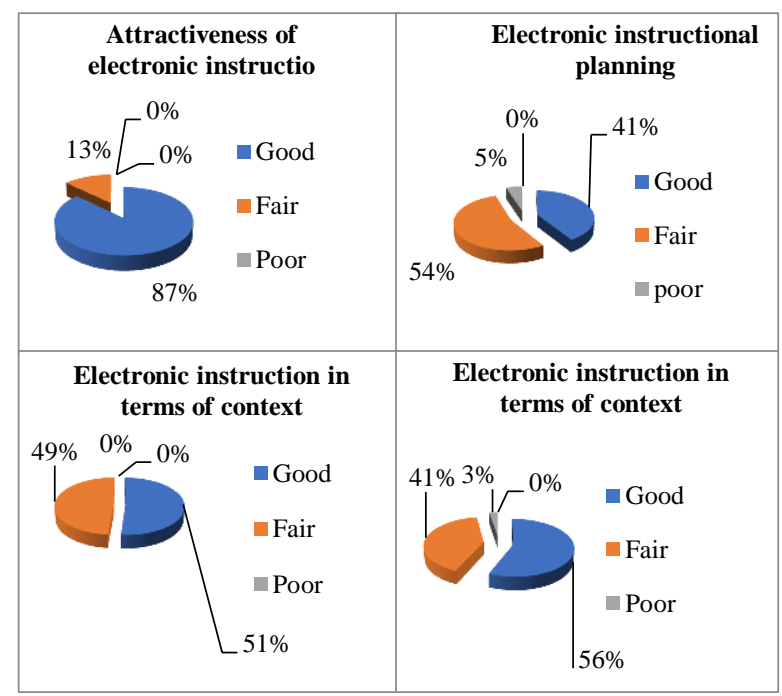

Fig. 1 Implementation of e-learning instruction in terms of attractiveness, planning, learning process, and context

The learning model in the resource economics lectures according to most students is interesting. The students' interest in attending e-learning lectures is very high. This is indicated by $87 \%$ of the students saying it is interesting. There are several benefits of implementing e-learning instruction, namely (1) Saving time on the learning process; (2) Reducing travel costs; (3) Saving overall education costs (infrastructure, equipment, books); (4) Reaching wider geographical areas; (5) Training learners to be more independent in gaining knowledge; (6) The use of instructor's time and HR is more effective. As seen from the planning, electronic-based learning or e-learning is in the good category, so are the aspects of the process and context which fall into the good category where $56 \%$ said the context is in accordance with the needs of the students.

The other aspects of assessment focused on this research are the input, process, product, and stability access. The result can be seen in Fig. 2.

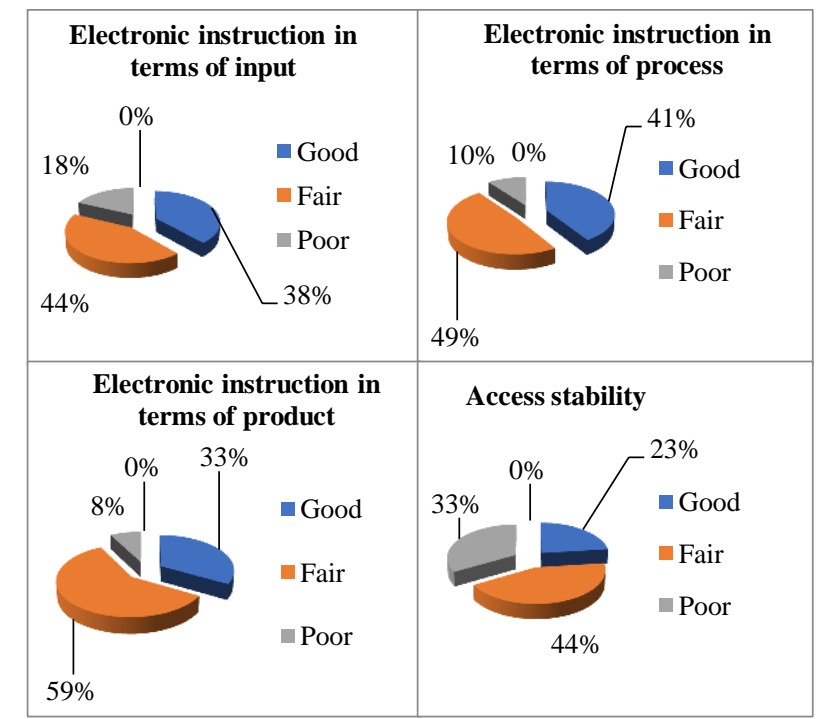

Fig. 2 Implementation of e-learning instruction in terms of input, process, product, and access stability
Lectures on resource economics courses using e-learning based instructional model seen from the input aspect where the learning tools being used and the content of lecture material are in the fair category with $44 \%$ saying it is fair and only $35 \%$ saying it is good. Furthermore, the aspect of the process is also in the fair category where the lecture process went well, as seen from the enthusiasm of the students attending the lecture and lecture procedures using the elearning model went quite smoothly by $49 \%$. The product aspect in e-learning based instruction is also in the fair category by $59 \%$ where the instruction uses the Online Website and there are weaknesses where students are still confused when opening the Online Website. Finally, the aspect of access is in the category of quite stable where the wifi connection and other electronic learning tools are available such as projectors and laptops for each student, but the problem is sometimes with the wifi being slow in accessing the Online Website. Electronic learning (e-learning) is a broader approach to learning that brings new opportunities for learning and teaching in various fields of education that are far from conventional classroom environments (Rodrigues et al., 2019).

E-learning instruction can run effectively if there is careful planning, in addition to being suitable to the learning objectives, it is also in accordance with the needs of students. In fact, the success of e-learning is related to a consistent and integrated effort between lecturers, students, faculty, support staff, and administrators.

To model students and learning resources with a good planning model (Ontology) online include helping in detail in order to produce more relevant material for students. In addition, it has the benefits of reusability, reasoning abilities, and supporting inference mechanisms which help improve recommendations for good learning methods (George \& Lal. 2019).

The access range, access speed, search for material access, and discussion also the concern in this research. It can be seen in Fig. 3.

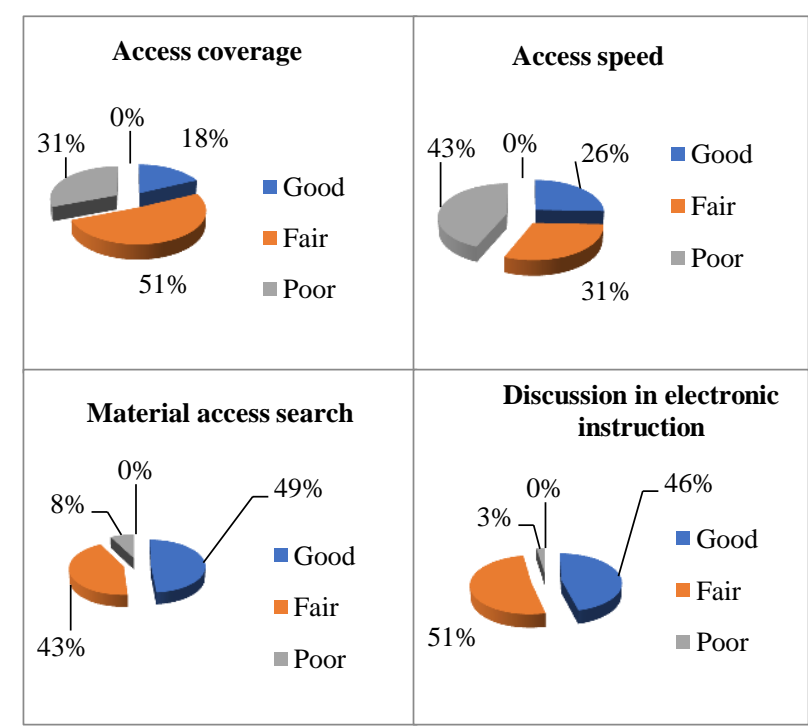

Fig. 3 Implementation of e-learning instruction in terms of access coverage, access speed, material access search, and discussion 
For website-based lectures, e-learning is designed using LMS as an open-source e-learning system for media access facilities by students as a media content processing application that is integrated with Microsoft PowerPoint. The method in the design of e-learning media uses a contextual approach. The e-learning media content in this development research consists of a login page, a home page, main menu, sub-menu material, learning videos, application material, and questions, as well as an access result page. (PDF) LMS-Based e-Learning Design. Judging from Fig. 3, it represents a sufficient access range of $43 \%$, lack of access speed which is $43 \%$ seen from the slow wifi connectivity provided by the campus. The aspect of material search is in the fair category by $43 \%$ as well as online media that are used have effectively become a medium of discussion for students in attending lectures in class.

The importance of material display in the learning process enables students to easily understand and be motivated towards lecture content. From the analysis, it was found that the majority or $67 \%$ of respondents stated that the display of e-learning based instructional materials in resource economics lectures is in a good category. Similarly, the availability of learning facilities is also considered good by $51 \%$, for example, the availability of LCD projectors, Wifi, Web learning, despite deficiencies in the quality of the media.

The display material, availability of facilities, and evaluation are the last aspects of the assessment in this research in which the result is figured in Fig. 4

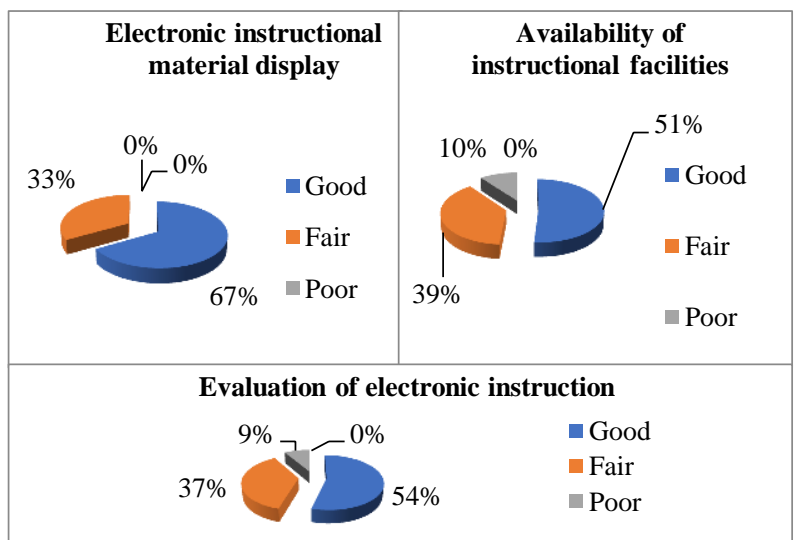

Fig. 4 The implementation of e-learning instruction in terms of materia display, availability of facilities, and evaluation

An e-learning system that is adaptive in providing personalized learning will improve students' academic performance. Where the main challenge in providing personalized learning models is finding the right match between individual characteristics and the sequence of learning content (Vanitha et al., 2019). E-learning programs can also effectively improve instructors and enhance their beliefs and attitudes (Katsagoni et al., 2019).

A more rigorous evaluation method for implementing elearning is required to understand the strengths and shortcomings of e-learning for education in the context of low-quality resources. Valid and reliable evaluations are the basis for guiding and improving e-learning interventions, increasing their sustainability (Barteit et al., 2020).
Evaluation of learning models in the resource economics lectures as a whole is categorized as being good where the respondents assessed all aspects by $54 \%$ which is in the good category and only $9 \%$ stated it is poor. It means that the elearning instructional model applied in resource economics lectures in economics education students at the Teacher Training and Education Faculty of Tanjungpura University is good and meets the needs of the students and can increase students' motivation and understanding in learning.

The results of evaluating the use of e-learning are important to underline that considering student emotions is very important for electronic learning (e-learning) systems. Some researchers have proposed that the system must encourage and apply the learner's emotions to the appropriate state. However, at first, the learner's emotions must be recognized by the system (Imani \& Montazer, 2019). Substantially the use of Internet technology for training and learning purposes has created the need to understand how various user engagements can influence the determinants of the design, acceptance, and use of Information Technology in learning (Baby \& Kannammal, 2019).

The activities of the evaluation of the implementation of elearning instruction are carried out with login tasks thereby increasing knowledge and skills, learning environment, and its influence. Evaluation of the implementation of e-learning is the process of analyzing the quality of the web-based (elearning) instructional process and the extent to which the achievement of the e-learning process can be felt by students. The evolution of the learning process is modeled by a series of learning experiences in which the aim is to be able to learn new skills along the sequence without forgetting what has been previously learned (Lesort et al., 2020). The development of learning models will continue to be done in order to create instruction according to the needs of the students and good learning objectives.

\section{CONCLUSIONS}

This research has provided evidence that (1) The implementation of learning models in e-learning based resource economics lectures in facing the industrial revolution 4.0 has been effective because there is careful planning. In addition to being suitable for the learning objectives, it is also in accordance with the needs of the students. The success of e-learning is related to a consistent and integrated effort between lecturers, students, faculty, support staff, and administrators. (2) The use of e-learning as a medium for learning resources, delivery of material, and assignment of tasks in the learning process of Resource Economics is still less than optimal. It indicates that the existing facilities and infrastructure have not been well utilized by its users, either by students, lecturers, or other related parties. And (3) the results of the evaluation of the implementation of the instructional model have shown a good category, meaning that the e-learning instructional model applied in the lectures of resource economics for economics education students is good and meets the needs of the students and can increase students' motivation and understanding in learning as a basis for facing the era industrial revolution 4.0. 


\section{REFERENCES}

Al-Fraihat, D., Joy, M., \& Sinclair, J. (2020). Evaluating elearning systems success: An empirical study. Computers in Human Behavior, 102, 67-86.

Baby, A., \& Kannammal, A. (2019). Network Path Analysis for developing an enhanced TAM model: a usercentric e-learning perspective. Computers in Human Behavior, 106081.

Barteit, S., Guzek, D., Jahn, A., Bärnighausen, T., Jorge, M. M., \& Neuhann, F. (2020). Evaluation of e-learning for medical education in low-and middle-income countries: A systematic review. Computers \& Education, 145, 103726.

Choudhury, S., \& Pattnaik, S. (2020). Emerging themes in elearning: A review from the stakeholders perspective. Computers \& Education, 144, 103657.

De Medio, C., Limongelli, C., Sciarrone, F., \& Temperini, M. (2020). MoodleREC: A recommendation system for creating courses using the moodle e-learning platform. Computers in Human Behavior, 104, 106168.

Farhan, W., Razmak, J., Demers, S., \& Laflamme, S. (2019). e-learning systems versus instructional communication tools: Developing and testing a new e-learning user interface from the perspectives of teachers and students. Technology in Society, 59, 101192.

George, G., \& Lal, A. M. (2019). Review of ontology-based recommender systems in e-learning. Computers \& Education, 142, 103642.

Imani, M., \& Montazer, G. A. (2019). A survey of emotion recognition methods with emphasis on E-Learning environments. Journal of Network and Computer Applications, 102423.

Katsagoni, C. N., Apostolou, A., Georgoulis, M., Psarra, G., Bathrellou, E., Filippou, C., \& Sidossis, L. S. (2019). Schoolteachers' nutrition knowledge, beliefs, and attitudes before and after an e-learning program. Journal of nutrition education and behavior, 51(9), 1088-1098.

Lesort, T., Lomonaco, V., Stoian, A., Maltoni, D., Filliat, D., \& Díaz-Rodríguez, N. (2020). Continual learning for robotics: Definition, framework, learning strategies, opportunities and challenges. Information Fusion, 58, 52-68.

Mayer, R. E. (2019). Searching for the role of emotions in elearning. Learning and Instruction, 101213.

Oosthuizen, C. (2016). Entrepreneurial intelligence: expanding schwab's four-type intelligence proposition to meaningfully address the challenges of the fourth industrial revolution. In Proceedings of the 28th Annual Conference of the Southern African Institute of Management Scientists, 370-383.

Rodrigues, H., Almeida, F., Figueiredo, V., \& Lopes, S. L. (2019). Tracking e-learning through published papers: A systematic review. Computers \& Education, 136, 87-98

Schwab, K. (2015) The Fourth Industrial Revolution: What It Means and How to Respond. Foreign Affairs: сайт. https://www. foreign affairs. com/articles/2015-1212/fourth-industrial-revolution (Accessed on September 15, 2019).

Shi, D., Wang, T., Xing, H., \& Xu, H. (2020). A learning path recommendation model based on a multidimensional knowledge graph framework for e-learning. Knowledge-Based Systems, 105618

Sukmadinata, Nana Syaodih. (2009). Metode Penelitian Pendidikan. Bandung: Remaja Rosdakarya.

Syamsuri, S. (2019). Analisis Konsep Theory Of Planned Behavior Terhadap Pembelajaran Wirausaha Dan Pendidikan Ekonomi Keluarga Pelaku Umkm. Jurnal PROFIT Kajian Pendidikan Ekonomi dan Ilmu Ekonomi, 6(2), 101-113.

Tortorella, G. L., Vergara, A. M. C., Garza-Reyes, J. A., \& Sawhney, R. (2020). Organizational learning paths based upon industry 4.0 adoption: An empirical study with Brazilian manufacturers. International Journal of Production Economics, 219, 284-294.

Vanitha, V., Krishnan, P., \& Elakkiya, R. (2019). Collaborative optimization algorithm for learning path construction in e-learning. Computers \& Electrical Engineering, 77, 325-338.

Vodovar, D., Ricard, J. D., Zafrani, L., Weiss, E., Desrentes, E., \& Roux, D. (2020). Évaluation d'un enseignement multimodal intégrant du e-learning dans l'apprentissage de la réanimation et de la médecine d'urgence au cours du second cycle des études médicales. La Revue de Médecine Interne. 